\title{
Ultrasound Mediated Functional Group Reduction and Chemoselective Studies by DMAB
}

\author{
VENKATESAN JAYAKUMAR $^{1 *}$ and MOHAMMED FAKRUDDIN ALI AHAMED ${ }^{2}$ \\ ${ }^{1 *}$ Department of Chemistry, Shri Vaishnav Institute of Science (SVIS), SVVV University, \\ Indore, MP, India \\ ${ }^{2}$ Department of Chemistry, Fathima Institute of Pharmacy, Kadapa, AP, India \\ svjayakumar1970@gmail.com
}

Received 8 January 2019 / Accepted 30 February 2019

\begin{abstract}
The current study emphasize about influence of ultrasound irradiation on moderately reactive $N, N$-dimethylaniline borane (DMAB) towards reduction of organic substrates like carboxylic acids, amides, imine, amino acids, aldehydes, ketones and esters. DMAB conveniently reduces the functional group within 15-25 min of sonication and it does not reduce the ester group even after 300 min of ultrasound irradiation. Besides these reducing properties the DMAB displays chemoselectivity towards different functional group. The amalgamation of borane species from amine borane and ultrasound irradiation provides ecofriendly and expeditious method for the reduction of functional groups.
\end{abstract}

Keywords: DMAB, Ultrasound irradiation, Sonication, Reduction, Chemoselectivity

\section{Introduction}

Boron reagents play a pivotal role in organic synthesis for hydroboration reaction ${ }^{1-4}$ as well as for functional group reduction ${ }^{5-8}$. Over the decades amine borane complexes received great attention due to its wide scope used in dye industry ${ }^{9}$, for various industrial applications ${ }^{10-13}$, in organic synthesis as a reagent for functional group conversions ${ }^{14-16}$. These complexes were efficiently used in hydrogen $\left(\mathrm{H}_{2}\right)$ storage fuel cells ${ }^{17,18}$ due to its stability and high gravimetric content of hydrogen. Jun Okuda et al., recently reports triphenylborane $\left(\mathrm{BPh}_{3}\right)$ able to catalyze the reduction of tertiary amides with hydrosilanes to give amines under mild condition with high chemoselectivity in the presence of ketones, esters, and imines ${ }^{19}$. Several tertiary amides were reduced by using one or two equivalents of various dialkylboranes, such as 9-borabicyclo[3.3.1]nonane (9-BBN), dicyclohexylborane $\left(\mathrm{Chx}_{2} \mathrm{BH}\right)$, disiamylborane $\left(\mathrm{Sia}_{2} \mathrm{BH}\right)^{20}$. But sterically hindered amine borane complexes of $\left(\mathrm{Chx}_{2} \mathrm{BH}\right)$ and $\left(\mathrm{Sia}_{2} \mathrm{BH}\right)$ reduces tertiary amides to corresponding aldehydes ${ }^{21}$.

The potential utility of amine borane complexes was limited due to its structural features, stability ${ }^{22}$ and lack of reactivity towards the functional groups ${ }^{23}$. The addition of 
acetic acid ${ }^{24}$, mineral acid $^{25}$ and Lewis acid ${ }^{26}$ is required to activate the stable amine borane complexes like triethylamine borane and pyridine borane. Kanth et al., prepared set of amine borane complexes from $N, N$-dialkyl anilines and $N, N$-dialkylamines, which is significantly more reactive than most other amine boranes ${ }^{27-29}$, this can be explained based on steric effects and electronic property of the groups attached to nitrogen atom which influence their reducing property ${ }^{27,30,31}$. Preparation of these amine borane complexes were cumbersome, which involves alkylation of aniline or mono alkyl aniline, which is delicate and time consuming ${ }^{31,33}$.

Rather attempt to prepare a new reactive amine borane complex, we choose the novel technique like microwave irradiation ${ }^{34,35}$, ultrasound irradiation (sonication) ${ }^{36}$ to activate moderately reactive DMAB complex towards hydroboration of unsaturated systems and reduction of functional groups. On the other hand no report was available on the use of $\mathrm{DMAB}$ as a reducing reagent for different functional groups under sonication condition. It has been well known that the activation of various chemical reactions by ultrasound, is not only enhances the selectivity and product yield but also shorten the reaction time and minimize the undesired side products ${ }^{37,38}$. Furthermore, with the ease of recovery and recycling of $N, N$-dimethylaniline after the reaction makes amine borane complex as an environmentally benign reagent.

\section{Experimental}

All chemicals were purchased from Fluka and Aldrich. Melting point of compounds were measured using a differential scanning calorimeter (Shimadzu DSC-50) and are uncorrected. Liquid substrates were distilled prior to use. All the NMR spectra were recorded on Bruker AVANCE spectrometer operating at $400 \mathrm{MHz}$ for ${ }^{1} \mathrm{H}$ NMR and $100 \mathrm{MHz}$ for ${ }^{13} \mathrm{C}$ NMR. The compounds were dissolved in $\mathrm{CDCl}_{3}, \mathrm{CD}_{3} \mathrm{OD}$ and DMSO and the chemical shifts were referenced to TMS. Coupling constants were calculated in hertz $(\mathrm{Hz})$. IR spectra were recorded on FTIR Shimadzu spectrometer. The mass spectra were recorded on EIShimadzu-GC-MS spectrometer. Elemental analyses were measured on a HERAEUS (CHNO, Rapid) analyzer.

\section{Preparation and stability of DMAB complex}

The DMAB complex was prepared (Scheme $1 \& 2$ ) by two methods ${ }^{4,5,16}$. The complexing ability of amine towards borane was monitored by ${ }^{11} \mathrm{~B}-\mathrm{NMR}$ spectroscopy. This reagent could be maintained under nitrogen atmosphere and apparently stable indefinitely at room temperature. In ${ }^{11} \mathrm{~B}$ NMR the amine borane complex showed a peak at $-4 \mathrm{ppm}$ (decoupled) and -4 to -9 ppm (coupled).<smiles>CN(C)c1ccccc1</smiles>

Scheme 1. Preparation of DMAB

\section{Mechanism}

The DMAB complex undergoes an initial dissociation to release reactive $\mathrm{BH}_{3}$ species under the influence of ultrasound irradiation, followed by reduction of functional group with borane. The results are summarized in Table 1. 


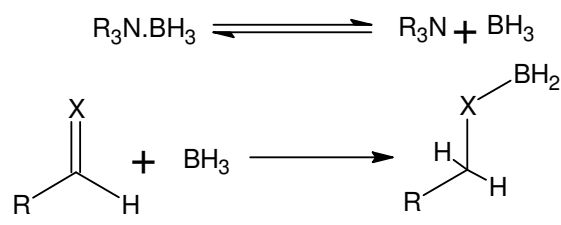

Where, $\mathrm{X}=$ functional groups

Scheme 2. The proposed mechanism of reduction of FG by DMAB

\section{Results and Discussion}

The aldehydes shown in entries 1,2 and 3 from Table 1 were comfortably reduced to the corresponding alcohols by DMAB 17 minutes period of time under sonication and quantitative yields were obtained. 1:3 Stoichiometry ratio was followed for the reduction. The halo aldehyde in entry 3 was reduced to the corresponding alcohol where halogen atom is intact. Reduction of cyclohexanone is slow at room temperature ( $24 \mathrm{~h}$ with only $80 \%$ completion as shown by TLC and Gas-burette analysis), however under ultrasound irradiation the reduction was completed in just 16 minutes and $96 \%$ yield of the corresponding alcohol was isolated (entry 5, Table 1). The same was observed in the case of acetophenone in 16 minutes (entry 4, Table 1).

Table 1. Reduction of representative functional groups with DMAB complex

\begin{tabular}{|c|c|c|c|c|c|}
\hline Entry & Substrate & $\begin{array}{l}\text { Time, } \\
\text { min. }\end{array}$ & $\begin{array}{c}\text { Stoichiometry } \\
\text { ratio } \\
\text { (DMAB:Sub) }\end{array}$ & Product & Yield \\
\hline 1 & Benzaldehyde & 15 & $1: 3$ & Benzyl alcohol & 90 \\
\hline 2 & $\begin{array}{l}\text { 2-Fluoro-4-bromo } \\
\text { benzaldehyde }\end{array}$ & 17 & $1: 3$ & $\begin{array}{l}\text { 2-Fluoro-4-bromo } \\
\text { benzyl alcohol }\end{array}$ & 1 \\
\hline 3 & $p$-Anisaldehyde & 16 & $1: 3$ & p-Anisyl alcohol & 94 \\
\hline 4 & Acetophenone & 16 & $1: 2$ & sec-Phenethyl alcohol & 98 \\
\hline 5 & Cyclohexanone & 16 & $1: 2$ & Cyclohexyl alcohol & 96 \\
\hline 6 & Benzoic acid & 18 & $1: 1$ & Benzyl alcohol & 93 \\
\hline 7 & Cinnamic acid & 20 & $1: 1,2: 1 \& 1: 2$ & Mixture of products & - \\
\hline 8 & Undecenoic acid & 20 & $1: 1,2: 1 \& 1: 2$ & Mixture of products & - \\
\hline 9 & Benzamide & 21 & $1: 1$ & Benzyl amine & 96 \\
\hline 10 & Acetanilide & 22 & $1: 1$ & $N$-Ethyl aniline & 94 \\
\hline 11 & $\begin{array}{l}\text { 4-Bromo } \\
\text { acetanilide }\end{array}$ & 22 & $1: 1$ & $\begin{array}{l}\text { 4-Bromo-N-Ethyl } \\
\text { aniline }\end{array}$ & 93 \\
\hline 12 & $L$-Valine & 24 & $1: 1$ & $L$-Valinol & 95 \\
\hline 13 & $L$-Leucine & 24 & $1: 1$ & $L$-Leucinol & 95 \\
\hline 14 & $L$-Proline & 22 & $1: 1$ & $L$-Prolinol & 96 \\
\hline 15 & Ethyl benzoate & 300 & $1: 1 \& 2: 1$ & No reaction & - \\
\hline 16 & $\begin{array}{l}\text { 4-Nitro methyl } \\
\text { benzoate }\end{array}$ & 300 & $1: 1 \& 2: 1$ & No reaction & - \\
\hline 17 & $\begin{array}{l}\text { 2-Hydroxy methyl } \\
\text { benzoate }\end{array}$ & 300 & $1: 1$ & No reaction & - \\
\hline 18 & Imine & 16 & $1: 1$ & Amine & 95 \\
\hline
\end{tabular}


Aromatic carboxylic acids (entries 6 and 7, Table 1) were readily reduced by DMAB to the corresponding alcohols in very good yields in a short period of time (21 minutes). A one to one ratio of reagents was used since one hydride is utilized for acid hydrolysis and further two hydrides are required for the carbonyl reduction. Tandem reduction / hydroboration was observed with cinnamic acid (entry 7, Table 1) and a mixture of products was formed based on GC analysis (tandem reduction / hydroboration of carboxyl group and double bond; the reduction of carboxyl group alone and the hydroboration of double bond alone).

DMAB conveniently reduces amide to amine in very good yields within 22 minutes under ultrasound irradiation. According to literature reports ${ }^{26,32,33}$, the reduction of benzamide, acetanilide with $N, N$-diethylaniline borane requires 7-13 hours under conventional methods. In these reduction 1:2 stoichiometry ratios was followed, because the reduced amine forms a complex with borane hence excess borane needed to make the reduction convenient.

The reduction of amino acids ${ }^{30}$ is considered important transformation in organic synthesis, the amino alcohol obtained in this transformation plays vital role in asymmetric synthesis ${ }^{28}$ and peptide synthesis. In the present study the reduction of three amino acids were focused namely valine, proline and leucine (entries 11-13, Table 1). Amine borane reagent conveniently reduces the amino acid to amino alcohol within 6 minutes in good yields. 1:2 Stoichiometry ratio was followed, the specific rotation value $\left[\alpha_{D}\right]$ matches with the literature value.

The reduction of imine esters (Schiff base) to amine esters ${ }^{8}$ in THF was facile with amine borane under ultrasound irradiation within 15 minutes in good yields.

It is noteworthy to mention that the reagent $\mathrm{DMAB}$ did not reduce ester functionality up to 300 minutes of ultrasound irradiation. This observation led us further to explore the chemoselective nature of DMAB.

\section{Chemoselectivity studies}

Based on the above results (Table 2) we under took these bi-functional substrates 4-nitrobenzaldehyde, nonomethyl hydrogen phthalate, 4-carbomethoxy acetanilide and imine ester for the study of chemoselective reduction with DMAB under ultrasound irradiation condition. DMAB selectively reduces the aldehyde, acid, amide and imine functionality within 20 minutes under ultrasound condition and without reducing the ester functional group.

Table 2. Chemoselective reduction of selected functional groups with DMAB

\begin{tabular}{ccccc}
\hline Entry & Substrate & $\begin{array}{c}\text { Time } \\
\text { min. }\end{array}$ & $\begin{array}{c}\text { Stoichiometry } \\
\text { ratio } \\
\text { (DMAB:Sub) }\end{array}$ & Product \\
\hline 1 & $\begin{array}{c}\text { 4-Nitrobenzaldehyde } \\
\text { Monomethyl hydrogen } \\
\text { phthalate }\end{array}$ & 17 & $1: 3$ & $\begin{array}{c}\text { 4-Nitrobenzyl alcohol } \\
\text { Methyl(2-hydroxymethyl) } \\
\text { benzoate }\end{array}$ \\
3 & 4-Carbomethoxy & 23 & $1: 1$ & $\begin{array}{c}\text { 4-Carbomethoxy- } N \text {-ethyl } \\
\text { aniline }\end{array}$ \\
acetanilide & 16 & $1: 1$ & $\begin{array}{c}\text { Amine ester } \\
\text { TRH is not observed, No } \\
\text { reduction of ester group, } \\
\text { only hydroboration of } \\
\text { double bond }\end{array}$ \\
& Imine ester & 20 & $1: 1$ &
\end{tabular}


In the case of ethyl-10-undecenoate selective hydroboration of double bond was observed, further confirmed by corresponding signal in ${ }^{11} \mathrm{~B}$ NMR at $75 \mathrm{ppm}$ and supported by the oxidation of trialkyl boron species with $\mathrm{NaOH} / \mathrm{H}_{2} \mathrm{O}_{2}$.

\section{Experimental procedure for functional group reduction ${ }^{4,5,16,31,34-36}$}

An oven dried, $50 \mathrm{~mL}$ RB flask fitted with a side arm capped by a rubber septum (to permit to add and removal of material with a hypodermic syringe) was equipped with microwave reflux condenser connected to a mercury bubbler by means of take-off adapter. DMAB in dry THF $10 \mathrm{~mL}(5.3 \mathrm{M}, 8.3 \mathrm{mmol})$ was added to the flask by syringe followed by compound in dry THF $(5.00 \mathrm{~mL}, 6.25 \mathrm{mmol})$ slowly during 5 minutes under nitrogen atmosphere. The contents were stirred for about 4-6 minutes under microwave irradiation. At appropriate time intervals, samples were withdrawn and hydrolyzed using $\mathrm{HCl}(2 \mathrm{M})$-glycerol-water mixture, the hydrogen evolved was measured using the gasimeter. Progress of the reaction was cross checked by GC, TLC analysis. In a number of cases, the reduction was carried out as described above to establish yield and stoichiometry. However, the reaction mixtures were then worked up depends on nature of substrate and to isolate and characterize the reaction products.

With aldehydes, ketone, carboxylic acid and ester reaction mixture was quenched with $\mathrm{HCl}(3 \mathrm{~N}, 10 \mathrm{~mL})$ and product was extracted with ether. The combined ether extracts were washed with $3 \mathrm{~N} \mathrm{HCl}$, water and brine and dried over anhydrous sodium sulphate, removal of solvent under vacuum gives crude product, which on purification by column chromatography yields pure product. In the case of amide, amino acid, imine, imine ester reaction mixture was quenched with potassium carbonate aqueous solution and product was extracted with ether. The crude product was obtained by simple acid / base manipulation, which was further purified by column chromatography, purity of the final product was obtained by HPLC method.

\section{Conclusion}

In recent years, structurally diversified novel amine borane reagents have been developed for the hydroboration of various unsaturated systems as well as reduction of functional groups, we demonstrated economical and convenient procedure for reduction of different functional groups by DMAB under ultrasound condition. It has certain advantages over the currently available borane reagents such as borane tetrahydrofuran (BTHF) and borane dimethyl sulfide (BMS), because of these reasons 1) quite concentrated 5.6 M, 2) convenient and comfortable to handle, 3) It makes available all three hydrides for the reduction of functional group, 4) environment friendly, not disagreeable odour, 5) thermally stable. In comparison with conventional methods sonication technique is a novel and efficient method to activate the DMAB complex towards the reduction of functional groups. Studies on stoichiometry, applications and limitations of this methodology are undergoing and will be reported in due course.

\section{Acknowledgement}

The authors are grateful to M. D. University, Rohtak for providing the necessary facilities. We also thank SAIF, Panjab University Chandigarh for providing the CHN analyses, ${ }^{1} \mathrm{H}$ NMR spectral data from CIL, Guru Jambeshwar University of Science and Technology, Hissar.

\section{References}

1. Brown H C and Subba Rao B C, J Org Chem., 1957, 22(9), 1136-1137; DOI:10.1021/jo01360a625 
2. Hawthorne M F, J Am Chem Soc., 1959, 81(21), 5836-5837;

DOI:10.1021/ja01530a077

3. Brown H C and Subba Rao B C, J Am Chem Soc., 1959, 81, 6423-6428; DOI:10.1021/ja01533a023

4. Pelter A, Smith K and Brown H C, Borane reagents, Academic press, London, 1988, 34.

5. Brown H C, Organic synthesis via boranes vol.1, Aldrich chemical company, Milwaukee, WI, 1997, 21.

6. Salunkhe A M and Burkhardt E R, Tet Lett., 1997, 38(9), 1519-1522; DOI:10. 1016/S0040-4039(97)00127-5

7. Salunkhe A M and Burkhardt E R, Tet Lett., 1997, 38, 1523-1526; DOI:10. 1016/S0040-4039(97)00128-7

8. Periasamy M, Kanth J V and Reddy C K, Perkin Trans A, 1995, 1, 427; DOI:10. 1039/P19950000427

9. Follet M, Chem Ind., 1986, 123.

10. Mallory G O and Hajdu J B, Electroless plating, Fundamentals and Applications, Noyes Publications/William Andrew, Orlando, Florida, 1990.

https://trove.nla.gov.au/work/6453483

11. Akahoshi H, Hitachi K, Murakami M, Wajima and Mito, US patent 1987, 4, 642, 161.

12. Bigelow H J, Burt R C and Rochester N Y, US patent 1968, 3, 361, 564.

13. Meller A, Gmelin Handbook of Inorganic and Organometallic Chemistry, Springer, Berlin, $19924^{\text {th }}$ Supplement, Vol. 3, 1 ISBN: 3540936734, Zustand

14. Lane C F, Aldrichimica Acta., 1973, 6, 51.

15. Barnes R P, Graham J H and Taylor M D, J Org Chem., 1958, 23(10), 1561-1562; DOI:10.1021/jo01104a610

16. Brown H C, Zaidlewicz M and Dalvi P V, Organometallics, 1998, 17(19), 4202-4205; DOI:10.1021/om980418u

17. Lane C F, N-B-H Survey, Con. \# DE-FC36-05GO 15060, Northern Arizona University, 2006

18. Rossin A and Peruzzini M, Chem Rev., 2016, 116(15), 8848-8872; DOI:10.1021 /acs.chemrev. 6b00043

19. Okuda J, Mashima K, Shirase S and Mukherjee D, Angewand Chemie Int Edn., 2016, 55(42), 13326-13329; DOI:10.1002/anie.201605236

20. Godjoian G and Singaram B, Tet let., 1997, 38(10), 1717-1720; DOI:10.1016/S00404039(97)00179-2

21. Bailey C L, Joh AY, Hurley Z Q, Anderson C L and Singaram B, J Org Chem., 2016, 81(9), 3619-3628; DOI:10.1021/acs.joc.6b00276

26. Brown H C and Murray L T, Inorg Chem., 1984, 23(18), 2746-2753;

DOI:10.1021/ic0018 6a008

27. Kelly H C, Giusto M B and Marchelli F R, J Am Chem Soc., 1964, 86(18), 3882-3884; DOI:10.1021/ja01072a063

28. Periasamy M, Kanth J V B and Prasad A S, Tetrahedron, 1994, 50(21), 6411-6416; DOI:10.10 16/S0040-4020(01)80657-8

29. Wuts P G M, Cabaj J E and Havens J L, J Org Chem., 1994, 59(21), 6470-6471; DOI:10.1021/jo00100a061

30. Kanth J V B and Periasamy M, Chem Commun., 1990, 1145-1147

DOI:10.1039/C39900001145

31. Kanth J V B, Aldrichimica Acta, 2002, 35, 57 
32. Brown H C, Kanth J V B and Zaidlewicz M, J Org Chem., 1998, 63(15), 5154-5163 DOI:10.1021/jo980362d

33. Brown H C, Kanth J V B, Dalvi P V and Zaidlewicz M, J Org Chem., 1999, 64(17), 6263-6274; DOI:10.1021/jo990379b

34. Jayakumar S V, Srinivas A K, Hiriyana G and Pati H, Rasayan J Chem., 2008, 1(2), 326-330.

35. Jayakumar S V and Ganesh S K, Orbital: Electron J Chem., 2014, 6, 56.

36. Jayakumar V and Ahamed M F A, Der Pharma Chemica, 2018, 10, 90-93.

37. Jacob J, Int J Chem., 2012, 4(6), 29-43; DOI:10.5539/ijc.v4n6p29

38. Puri S, Kaur B, Parmar A and Kumar H, Curr Org Chem., 2013, 17(16), 1790-1828 DOI:10.2174/13852728113179990018. 